\title{
The Low Energy Auger Electron Spectroscopy Lines as an Index of the Ba Overlayer Order on the Ni(110) Surface
}

\author{
D. Vlachos, M. Kamaratos, and S. D. Foulias \\ Department of Physics, University of Ioannina, P.O. Box 1186, 45110 Ioannina, Epirus, Greece \\ Correspondence should be addressed to D. Vlachos; dvlachos@cc.uoi.gr
}

Received 31 October 2013; Revised 3 February 2014; Accepted 18 February 2014; Published 26 March 2014

Academic Editor: Hakan Arslan

Copyright ( 2014 D. Vlachos et al. This is an open access article distributed under the Creative Commons Attribution License, which permits unrestricted use, distribution, and reproduction in any medium, provided the original work is properly cited.

\begin{abstract}
We investigate the interaction of $\mathrm{Ba}$ with the $\mathrm{Ni}(110)$ surface at elevated temperatures by means of Auger electron spectroscopy and low energy electron diffraction. The results show that annealing of the substrate causes desorption and ordering of the initially amorphous overlayer, resulting in $\mathrm{c}(2 \times 2)$ and $(2 \times 2)$ structures. It is observed that the induced ordering crucially affects the lineshape of the double Auger transition line $\mathrm{Ba}(73 \mathrm{eV}) \mathrm{N}_{45} \mathrm{O}_{23} \mathrm{P}_{1}$, establishing this line as an index of ordering of the $\mathrm{Ba}$ overlayer. The underlying physics of this effect is discussed.
\end{abstract}

\section{Introduction}

Auger electron spectroscopy (AES) is one of the most fundamental techniques in surface science providing chemical, growth mode, and coverage information $[1,2]$. Despite the emerging wealth of knowledge coming from this surface analytical technique, to the best of our knowledge, structural information seems to be very limited. Although there are reports for different structural phases of $\mathrm{C}$ and Si studied by AES [3-5], in the case of metals, analogous contributions are rare [6]. It would be a useful application of AES if the lineshape can be correlated to surface structural changes, either to order-order or to order-disorder transitions. This is the main issue of this work.

The material system, which we use in order to investigate the potential use of AES as a structural tool, is $\mathrm{Ba}$ on the $\mathrm{Ni}(110)$ surface. This system has been extensively studied before $[7,8]$, and the present study is an extension of our previous work [7]. That work shows that Ba develops in successive layers on the $\mathrm{Ni}(110)$ surface, with the first one strongly interacting with the substrate and comprising a mixture of random $c(2 \times 2)$ domains and disordered adatoms. On the other hand, the second layer is disordered and more weakly bound. Substrate annealing at $\sim 500^{\circ} \mathrm{C}$ opens up a kinetic channel, where $\mathrm{Ba}$ atoms are transferring from the second layer to the first one, increasing the $c(2 \times 2)$ ordering of $\mathrm{Ba}$. Depending on the initial coverage, desorption of $\mathrm{Ba}$ is also observed. Stronger annealing up to $\sim 800^{\circ} \mathrm{C}$ ends up with a substantial remaining subsurface Ba quantity $(\sim 0.35 \mathrm{ML})$, with an unclear symmetry. In this work, the remaining barium on the surface presents a newly observed $(2 \times 2)$ symmetry, which might be the previously unidentified one. More importantly, by studying the thermal stability of the $\mathrm{Ba}$ overlayer on the $\mathrm{Ni}(110)$ surface, we demonstrate the sensitivity of the low energy Auger electron spectrum to the overlayer order. Specifically, we correlate the lineshape of the double $\mathrm{Ba}(73 \mathrm{eV}) \mathrm{N}_{45} \mathrm{O}_{23} \mathrm{P}_{1}$ core-core-valence Auger transition line with amorphous and ordered barium structures.

\section{Materials and Methods}

The experiments were carried out in a typical ultrahigh vacuum (UHV) system equipped with AES and low energy electron diffraction (LEED) techniques. The base pressure in the UHV chamber was of the order of $10^{-10}$ Torr, while as a substrate a $\mathrm{Ni}(110)$ single crystal was used. The specimen could be heated by a Ta tape firmly attached to the back side of the crystal and uniformly pressed between the crystal and a Ta metallic case. The temperature of the crystal could be measured by a NiCr-CrAl thermocouple, spot-welded onto the center of the Ta case, and calibrated by an infrared pyrometer. For the crystal cleaning process, an argon ion gun 
was used for sputtering at energy $2 \mathrm{keV}$, at partial pressure $\sim 5 \times 10^{-5}$ Torr, and at sputtering time $\sim 20 \mathrm{~min}$. After the sputtering process and a following annealing at $700 \mathrm{~K}$, a sharp $(1 \times 1)$ LEED pattern could be observed. Barium deposition was carried out by using a commercial evaporation SAES Getters source. The AES measurements were performed with a primary electron beam of energy $2 \mathrm{keV}$ and anode current $15 \mu \mathrm{A}$, while the electrons were collected and analyzed by a Varian cylindrical mirror analyzer (CMA). The AES signal was recorded in the first derivative mode, $d N(E) / d E$, with modulation voltage $5 \mathrm{~V}$, sensitivity in lock-in amplifier $10 \mu \mathrm{V}$, and photomultiplier voltage $1.750 \mathrm{kV}$. The $\mathrm{Ba}$ deposition was done in steps of $2 \mathrm{~min}$ deposition time, with the evaporation source at constant current $6.5 \mathrm{~A}$. Based on this and combining the previous AES, LEED, thermal desorption spectroscopy, and work function results [7], the barium coverage could be estimated in monolayers with a flux of $\sim 0.1 \mathrm{ML} / 2 \mathrm{~min}$. The quantity of $1 \mathrm{ML}$ is defined as the atomic density of the $\mathrm{Ba}(110)$ plane equal to $0.57 \times 10^{15} \mathrm{at} / \mathrm{cm}^{2}$, which is the densest atomic array of barium on the $\mathrm{Ni}(110)$ surface.

\section{Results and Discussion}

First we deposited $20 \mathrm{~min}(\sim 1 \mathrm{ML})$ of $\mathrm{Ba}$ on the clean $\mathrm{Ni}(110)$ surface, and we performed annealing for $\sim 2 \mathrm{~min}$ increasing the substrate temperature in steps of $50 \mathrm{~K}$ each time. The AES measurements were performed when the substrate was cooled down to $\sim 320 \mathrm{~K}$. Figure 1 presents the low energy AES curves of the $\mathrm{Ba}(1 \mathrm{ML}) / \mathrm{Ni}(110)$ surface after annealing at different temperatures. Next to each curve the observed symmetry by LEED is noticed. In these spectra we basically record the $\mathrm{Ni}(61 \mathrm{eV}) \mathrm{M}_{23} \mathrm{M}_{45} \mathrm{M}_{45}$, a core-valence-valence Auger transition line (ATL), and the $\mathrm{Ba}(73 \mathrm{eV}) \mathrm{N}_{45} \mathrm{O}_{23} \mathrm{P}_{1}$, a core-core-valence ATL. We also record the intense $\mathrm{Ba}(57 \mathrm{eV}) \mathrm{MMN}$ line, but this is strongly overlapping with the $\mathrm{Ni}(61 \mathrm{eV})$ line and it cannot be analyzed properly. This overlapping, in combination with the small electron mean free path of the $\mathrm{Ni}(61 \mathrm{eV})$, may be the main reason why this intense ATL almost vanishes after only $1 \mathrm{ML}$ of $\mathrm{Ba}$ deposition. Based on the LEED observations, within the $300-650 \mathrm{~K}$ range, the $\mathrm{Ba}$ overlayer was amorphous. On further annealing, however, between 650 and $850 \mathrm{~K}$, the $\mathrm{Ba}$ overlayer exhibits a $\mathrm{c}(2 \times 2)$ pattern. This phase of $\mathrm{Ba}$ is known from a previous work [7]. For annealing from 850 to $950 \mathrm{~K}$ the $\mathrm{c}(2 \times 2)$ order deteriorated, while from 950 to $1050 \mathrm{~K}$ a new $(2 \times 2)$ pattern appears. While the $\mathrm{c}(2 \times 2)$ structure was seen before [7], the $(2 \times 2)$ one is observed for the first time.

Figure 2 shows the LEED patterns of $(\mathrm{a})(1 \times 1)$ clean $\mathrm{Ni}(110)$ at energy $147 \mathrm{eV}$, (b) $\mathrm{Ba}-\mathrm{c}(2 \times 2)$ at $124 \mathrm{eV}$ after annealing at $650 \mathrm{~K}$, and (c) $\mathrm{Ba}-(2 \times 2)$ at $124 \mathrm{eV}$ after annealing at $1000 \mathrm{~K}$, for $\mathrm{Ba}(1 \mathrm{ML})$ deposition on the $\mathrm{Ni}(110)$ surface at room temperature. By taking into account the metallic diameters of $\mathrm{Ba}$ and $\mathrm{Ni}$ atoms (4.34 and $2.48 \AA$, resp.), structural models of the amorphous as well as the ordered barium structures are illustrated in Figure 3 . The $c(2 \times 2)$ structure in Figure 3(b) represents the complete monolayer of $\mathrm{Ba}(1 \mathrm{ML})$ on the nickel surface, since it is the densest atomic array of $\mathrm{Ba}$ adatoms on the $\mathrm{Ni}(110)$ surface in one layer. On the other hand, the $(2 \times 2)$ structure represents half of the monolayer

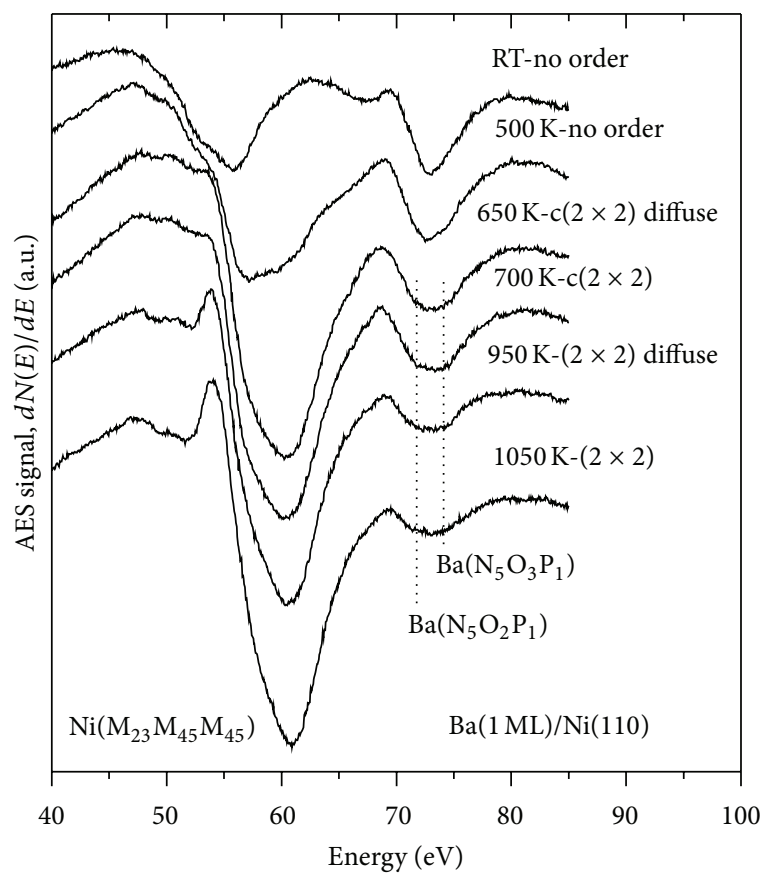

FIgURE 1: Low energy AES spectra of the $\mathrm{Ba}(1 \mathrm{ML}) / \mathrm{Ni}(110)$ surface after annealing at different temperatures. Next to each curve the observed symmetry by LEED is noticed.

$(0.5 \mathrm{ML})$ of $\mathrm{Ba}$. The transition from $\mathrm{c}(2 \times 2)$ to $(2 \times 2)$ occurs at the same time with $\mathrm{Ba}$ desorption from the nickel surface.

Going back to Figure 1, attention is drawn to the change of the $\mathrm{Ba}(73 \mathrm{eV})$ lineshape as the substrate is annealed and the ordering of the Ba overlayer is established. Specifically, as long as the $\mathrm{Ba}$ overlayer is amorphous and at room temperature, the $\mathrm{Ba}(73 \mathrm{eV})$ ATL appears to be a single and rather sharp line. A weak peak at $\sim 68 \mathrm{eV}$ is due to the oxidation of a small portion of the barium overlayer, owing to the high reactivity of barium to chemisorbed oxygen from the environment $[9,10]$. This peak disappears at temperatures $>500 \mathrm{~K}$ indicating a dissociation of $\mathrm{BaO}$ on the surface. As the $\mathrm{c}(2 \times 2)$ symmetry develops, the $\mathrm{Ba}(73 \mathrm{eV})$ ATL becomes flatter consisting of two contributions. The following $(2 \times 2)$ structure at higher temperatures sustains the same lineshape. We need to point out that the $\mathrm{O}(510 \mathrm{eV})$ ATL was negligible with the appearance of the $c(2 \times 2)$ structure and absent with the $(2 \times 2)$ one.

We repeated the annealing experiments for higher $\mathrm{Ba}$ coverage at the $2.25 \mathrm{ML}$, and as Figure 4 illustrates, the amorphous layer of $\mathrm{Ba}$ at $600 \mathrm{~K}$ gives a rather flat $\mathrm{Ba}(73 \mathrm{eV})$ ATL, while both the $c(2 \times 2)$ and $(2 \times 2)$ structures cause a split of the line into another two with energy distance $\sim 2.5 \mathrm{eV}$. A similar low energy Ba Auger double line has been recorded for a $c(2 \times 2)$ barium structure on the $\mathrm{W}(110)$ surface [11]; however, its origin was not commented upon. Thus, out of the comparison between the amorphous and the ordered Ba overlayers, it is obvious that the overlayer order affects drastically the $\mathrm{Ba}(73 \mathrm{eV})$ lineshape. To the best of our knowledge, no similar effect has been observed before. 


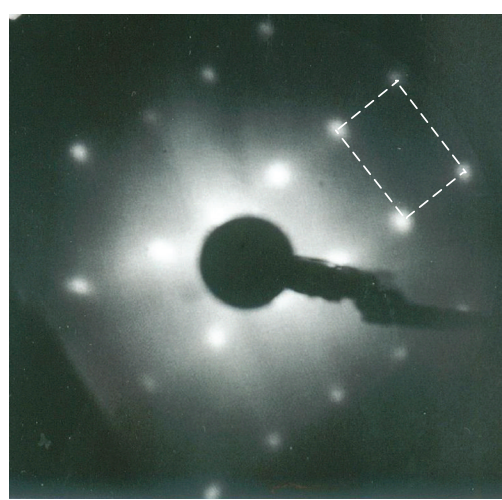

(a)

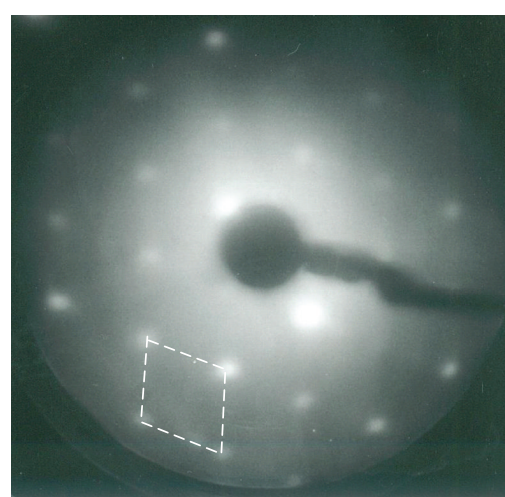

(b)

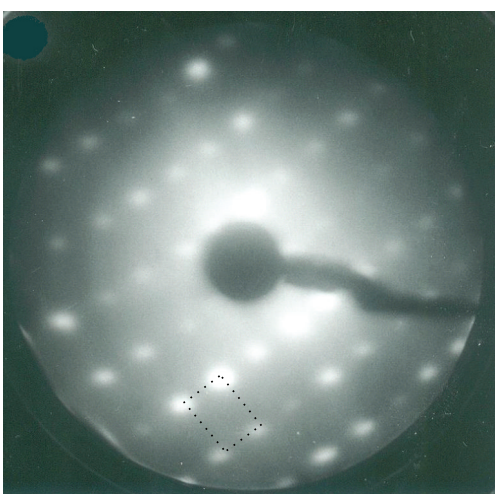

(c)

Figure 2: The LEED patterns of (a) $(1 \times 1)$ clean Ni(110) at energy $147 \mathrm{eV}$, (b) $\mathrm{c}(2 \times 2)$ at $124 \mathrm{eV}$ after annealing at $650 \mathrm{~K}$, and (c) $(2 \times 2)$ at $124 \mathrm{eV}$ after annealing at $1000 \mathrm{~K}$, for $\mathrm{Ba}(1 \mathrm{ML})$ deposition on the $\mathrm{Ni}(110)$ surface.

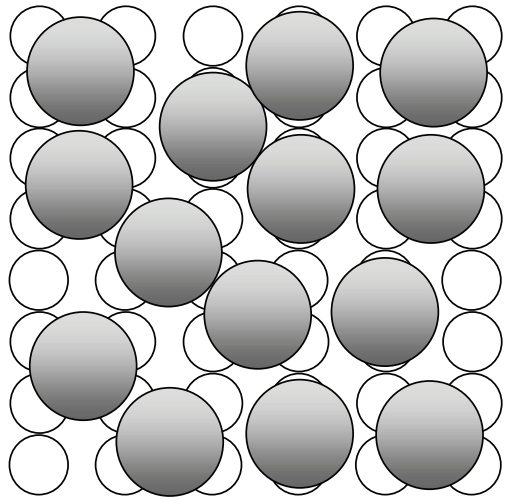

(a)

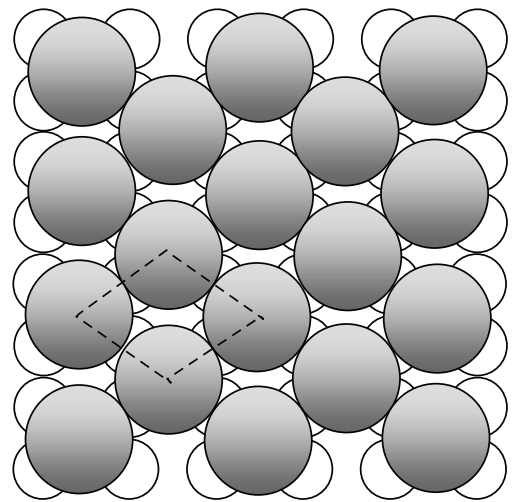

(b)
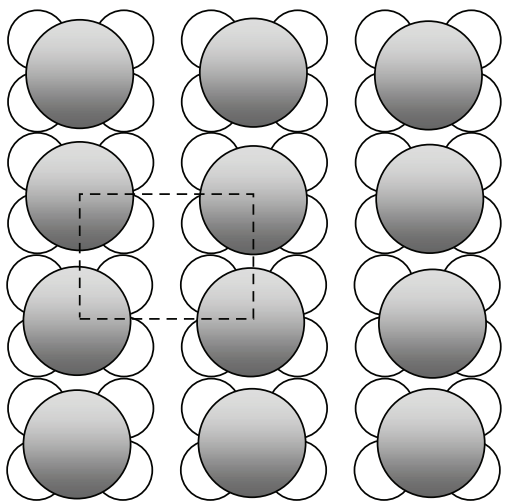

(c)

Figure 3: The structural adsorption models of the (a) disordered, (b) Ba-c( $2 \times 2)$, and (c) $\mathrm{Ba}-(2 \times 2)$, on the Ni(110) surface. The circles in the models represent the atoms of $\mathrm{Ba}$ (dark circles) and $\mathrm{Ni}$ (empty circles). The sizes of the circles are proportional to the metallic diameters of $\mathrm{Ba}$ and $\mathrm{Ni}$ atoms. The unit cells are noticed with the dashed lines.

Let us try to explain why this effect happens. The $\mathrm{Ba}(73 \mathrm{eV}) \mathrm{N}_{45} \mathrm{O}_{23} \mathrm{P}_{1}$ Auger transition line is a core-corevalence transition, which involves the $4 \mathrm{~d}, 5 \mathrm{p}$, and $6 \mathrm{~s}$ atomic orbitals. As previous photoemission measurements have shown, both the $4 \mathrm{~d}$ and $5 \mathrm{p}$ orbitals are split into two states each one due to the spin-orbit coupling [12]. Thus the first orbital participates in the Auger transition with the $4 \mathrm{~d}_{3 / 2}$ and $4 \mathrm{~d}_{5 / 2}$ states, while the second one participates with the $5 \mathrm{p}_{1 / 2}$ and $5 p_{3 / 2}$ states. In this manner, the emitted Auger electrons from the $6 \mathrm{~s}$ orbital should appear with four different kinetic energies, which are listed in Table 1 [13]. In our AES spectra the split of the $\mathrm{Ba}(73 \mathrm{eV}) \mathrm{N}_{45} \mathrm{O}_{23} \mathrm{P}_{1}$ line seems to fit well with the $\mathrm{N}_{5} \mathrm{O}_{2} \mathrm{P}_{1}$ and $\mathrm{N}_{5} \mathrm{O}_{3} \mathrm{P}_{1}$ Auger transitions. The contribution of both of these lines is expected to be dominant compared to that of the other two $\left(\mathrm{N}_{4} \mathrm{O}_{2} \mathrm{P}_{1}\right.$ and $\left.\mathrm{N}_{4} \mathrm{O}_{3} \mathrm{P}_{1}\right)$.

In general, the energetic position of an Auger electron peak is a characteristic of the element (i.e., the binding energies of the three electronic states involved) and its chemical state. The width of the peak including fine structure, on the other hand, depends on the local electron density of the valence states adjacent to the adsorption site and the localization of the final state holes. Particularly the width is
TABle 1: The atomic configurations of the $\mathrm{Ba}\left(\mathrm{N}_{45} \mathrm{O}_{23} \mathrm{P}_{1}\right)$ Auger transition line. The kinetic energies take into account the core-hole effect [13].

\begin{tabular}{lcc}
\hline Auger transition & Atomic orbitals & Kinetic energy $(\mathrm{eV})$ \\
\hline $\mathrm{N}_{4} \mathrm{O}_{2} \mathrm{P}_{1}$ & $4 \mathrm{~d}_{3 / 2}-5 \mathrm{p}_{1 / 2}-6 \mathrm{~s}$ & 74.5 \\
$\mathrm{~N}_{4} \mathrm{O}_{3} \mathrm{P}_{1}$ & $4 \mathrm{~d}_{3 / 2}-5 \mathrm{p}_{3 / 2}-6 \mathrm{~s}$ & 76.5 \\
$\mathrm{~N}_{5} \mathrm{O}_{2} \mathrm{P}_{1}$ & $4 \mathrm{~d}_{5 / 2}-5 \mathrm{p}_{1 / 2}-6 \mathrm{~s}$ & 71.5 \\
$\mathrm{~N}_{5} \mathrm{O}_{3} \mathrm{P}_{1}$ & $4 \mathrm{~d}_{5 / 2}-5 \mathrm{p}_{3 / 2}-6 \mathrm{~s}$ & 73.5 \\
\hline
\end{tabular}

strongly related to the lifetime of the three electronic states involved. In principle the energy width $\Delta E$ of an Auger electron peak is given as

$$
\Delta E=\left(\Delta E_{X Y Z}^{2}+\Delta E_{a}^{2}\right)^{1 / 2},
$$

where $\Delta E_{X Y Z}$ is the natural or inherent width of the Auger transition and $\Delta E_{a}$ is the analyzer resolution all expressed in FWHM [14]. Equation (1) assumes that all the energy widths have a Gaussian lineshape. In our experiments the CMA used was always operating under the same settings 


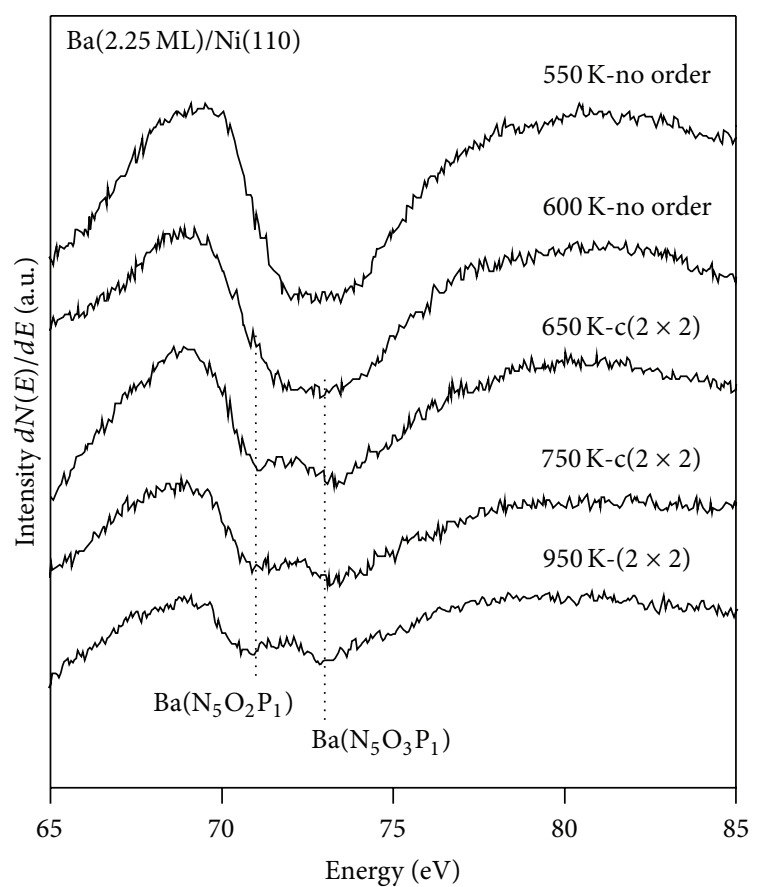

FIgure 4: The $\mathrm{Ba}(73 \mathrm{eV}) \mathrm{N}_{45} \mathrm{O}_{23} \mathrm{P}_{1}$ core-core-valence Auger transition line of the $\mathrm{Ba}(2.25 \mathrm{ML}) / \mathrm{Ni}(110)$ surface after annealing at different temperatures. Next to each curve the observed symmetry by LEED is noticed.

(modulation voltage, sweep time, sensitivity, etc.). Thus the only term that could possibly change the width of the recorded Auger $\mathrm{Ba} \mathrm{N}_{45} \mathrm{O}_{23} \mathrm{P}_{1}$ line should be the $\Delta E_{X Y Z}$ term. However, the natural width is not expected to change with the structure. Yet, the phase transition from amorphous to ordered barium can induce the following effect: in the amorphous phase the Auger electron emitting atoms have a range of different coordination numbers resulting in slightly shifted and overlapping Auger peaks, causing an effective broadening of the measured spectrum. The ordered structure, on the other hand, is characterized by a constant coordination number resulting in well-defined, in energy, peaks. In other words, the more ordered the atomic environment around the probe atom is, the narrower the measured FWHM is. From the discussion above, we conclude that the recorded splitting of the $\mathrm{Ba} \mathrm{N} \mathrm{N}_{45} \mathrm{O}_{23} \mathrm{P}_{1}$ line for both the $\mathrm{c}(2 \times 2)$ and $(2 \times 2)$ structures can be assigned to the smaller observed width of the Auger electron transition. In that sense, the lineshape of the Auger $\mathrm{Ba} \mathrm{N}_{45} \mathrm{O}_{23} \mathrm{P}_{1}$ line may reflect the order of the barium overlayer.

\section{Conclusions}

In this work we studied the effects of the annealing temperature on the stabilization of different superstructures for $\mathrm{Ba}$ overlayer on the $\mathrm{Ni}(110)$ surface. A correlation between the overlayer order and the corresponding $\mathrm{Ba}$ AES lineshape was investigated. It was found that the lineshape of the low energy Ba $\mathrm{N}_{45} \mathrm{O}_{23} \mathrm{P}_{1}$ Auger transition line is strongly influenced by the disorder-order transition of the barium adsorbate.
Therefore, it appears that, under certain conditions, AES can differentiate ordered from amorphous overlayers.

\section{Conflict of Interests}

The authors declare that there is no conflict of interests regarding the publication of this paper.

\section{References}

[1] D. Briggs and M. P. Seah, Practical Surface Analysis, vol. 1, John Wiley \& Sons, Chichester, UK, 2nd edition, 1990.

[2] C. Argile and G. E. Rhead, "Adsorbed layer and thin film growth modes monitored by Auger electron spectroscopy," Surface Science Reports, vol. 10, no. 6-7, pp. 277-356, 1989.

[3] P. G. Lurie and J. M. Wilson, "The diamond surface. II. Secondary electron emission," Surface Science, vol. 65, no. 2, pp. 476-498, 1977.

[4] A. Hoffman, S. Prawer, and R. Kalish, "Structural transformation of diamond induced by 1-keV Ar-ion irradiation as studied by Auger and secondary-electron spectroscopies and totalsecondary- electron-yield measurements," Physical Review B, vol. 45, no. 22, pp. 12736-12745, 1992.

[5] C. P. Lund, B. W. Clare, P. J. Jennings, J. C. L. Cornish, and G. T. Hefter, "An experimental and theoretical study of Auger lineshapes in hydrogenated amorphous silicon structures," Surface Science, vol. 303, no. 1-2, pp. 266-276, 1994.

[6] R. Siuda, H. Engelhard, A. Goldmann, M. Cyrankiewicz, and G. Balcerowska, "PCA-based analysis of X-ray-excited Auger spectra from non-ordered $\operatorname{Ag}(110)$," Czechoslovak Journal of Physics, vol. 53, no. 1, pp. 63-67, 2003.

[7] D. Vlachos, S. D. Foulias, S. Kennou, C. Pappas, and C. Papageorgopoulos, "Ba deposition on Ni(110)," Surface Science, vol. 331-333, pp. 673-678, 1995.

[8] M. Kamaratos, D. Vlachos, and S. D. Foulias, "Electronic properties of barium ultrathin layers on the $\mathrm{Ni}(11 \mathrm{O})$ surface," Surface Review and Letters, vol. 12, no. 5-6, pp. 721-725, 2005.

[9] G. A. Haas, C. R. K. Marrian, and A. Shih, "Interatomic Auger analysis of the oxidation of thin Ba films. I. Characterization of the low energy Auger spectrum," Applications of Surface Science, vol. 16, no. 1-2, pp. 125-138, 1983.

[10] D. Vlachos, N. Panagiotides, and S. D. Foulias, "Auger electron spectroscopy and work function characterization of oxygen adsorption on Ba-covered $\mathrm{Ni}(110), "$ Journal of Physics: Condensed Matter, vol. 15, no. 47, pp. 8195-8206, 2003.

[11] D. R. Mueller, R. L. Kurtz, R. L. Stockbauer, and T. E. Madey, "A photoemission study of $\mathrm{BaO}$ overlayers adsorbed on $\mathrm{W}(110)$ and their interaction with $\mathrm{H}_{2} \mathrm{O}, \mathrm{CO}_{2}$, and $\mathrm{O}_{2}$," Surface Science, vol. 237, pp. 72-86, 1990.

[12] D. Vlachos, M. Kamaratos, and S. D. Foulias, "Barium and oxygen interaction on the $\mathrm{Ni}(110)$ surface at low coverages studied by soft $\mathrm{x}$-ray photoemission spectroscopy: Ba negative binding energy shifts and their correlation with Auger electron spectroscopy shifts," Journal of Physics: Condensed Matter, vol. 18, no. 30, pp. 6997-7011, 2006.

[13] W. A. Coghlan and R. E. Clausing, "Auger catalog calculated transition energies listed by energy and element," Atomic Data and Nuclear Data Tables, vol. 5, no. 4, pp. 317-469, 1973.

[14] K. Sevier, Low Energy Electron Spectrometry, Wiley-Interscience, New York, NY, USA, 1972. 

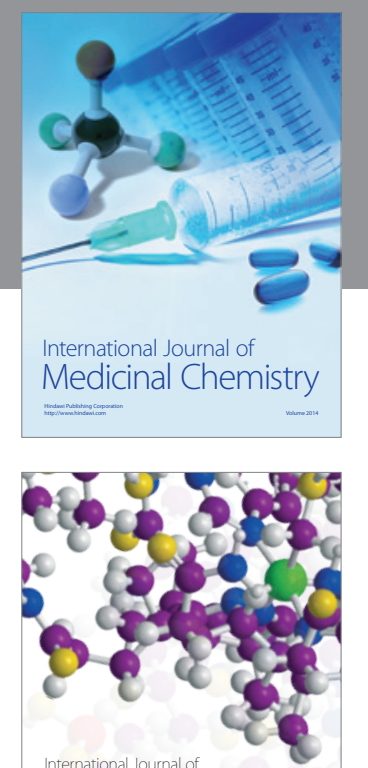

\section{Carbohydrate} Chemistry

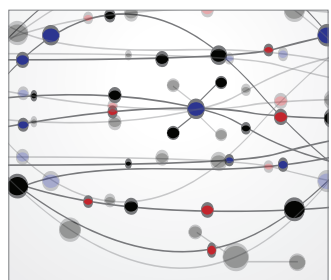

The Scientific World Journal
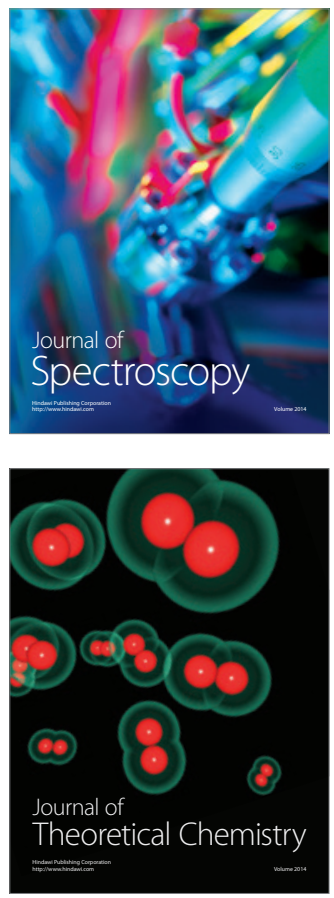
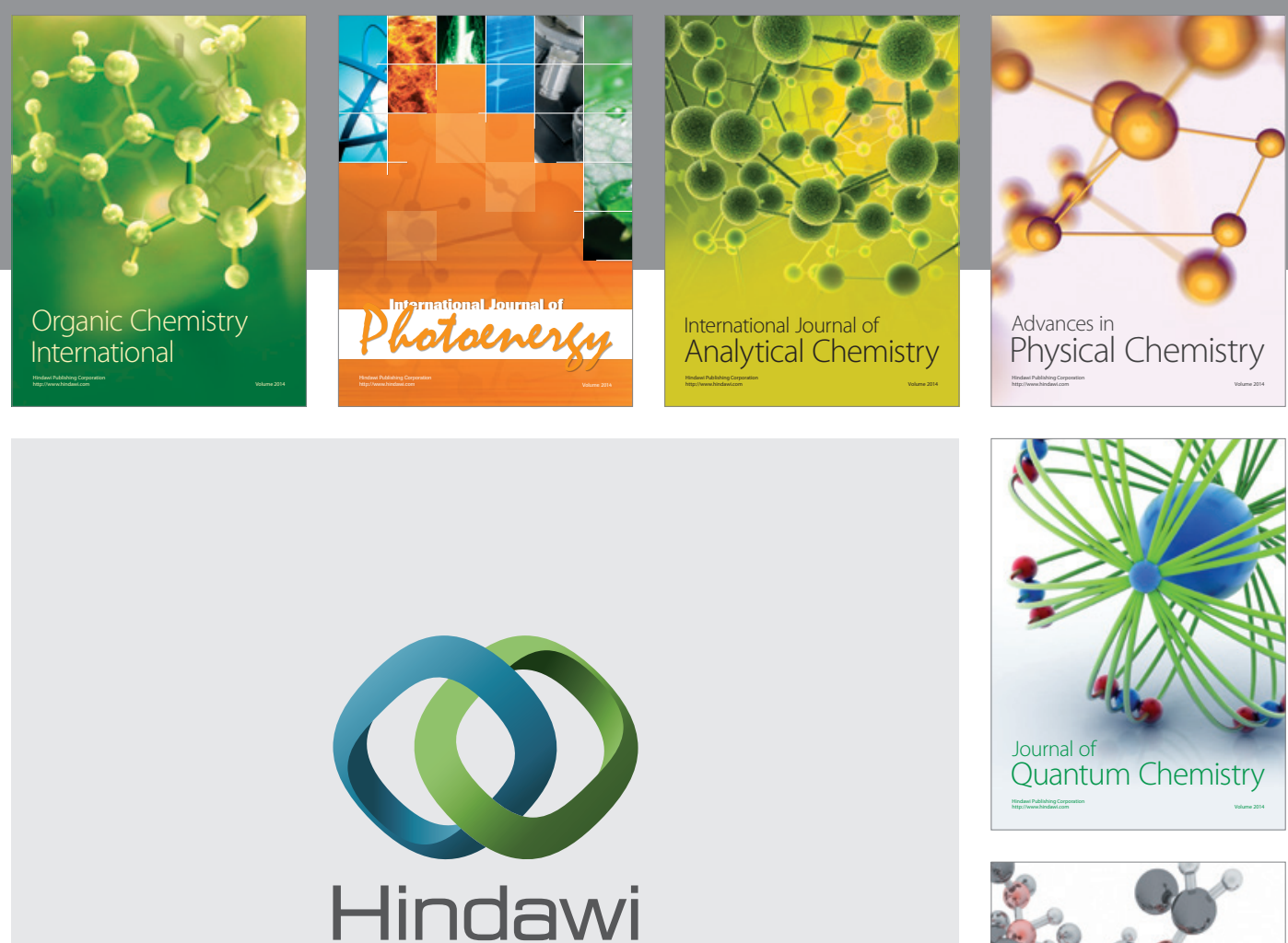

Submit your manuscripts at

http://www.hindawi.com

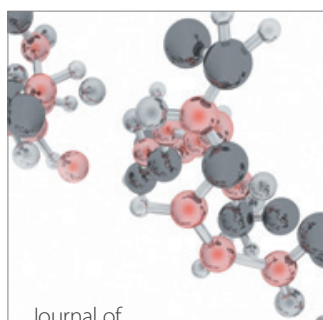

Analytical Methods

in Chemistry

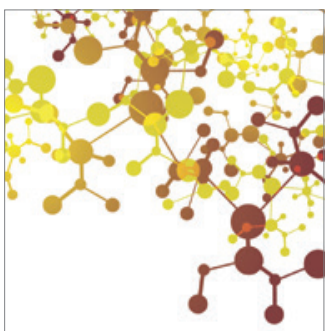

Journal of

Applied Chemistry

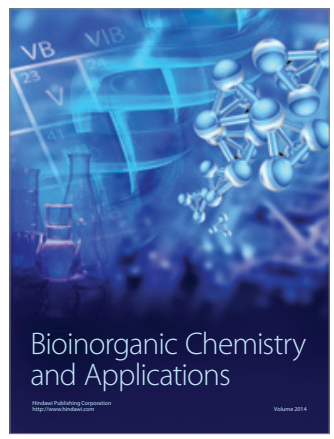

Inorganic Chemistry
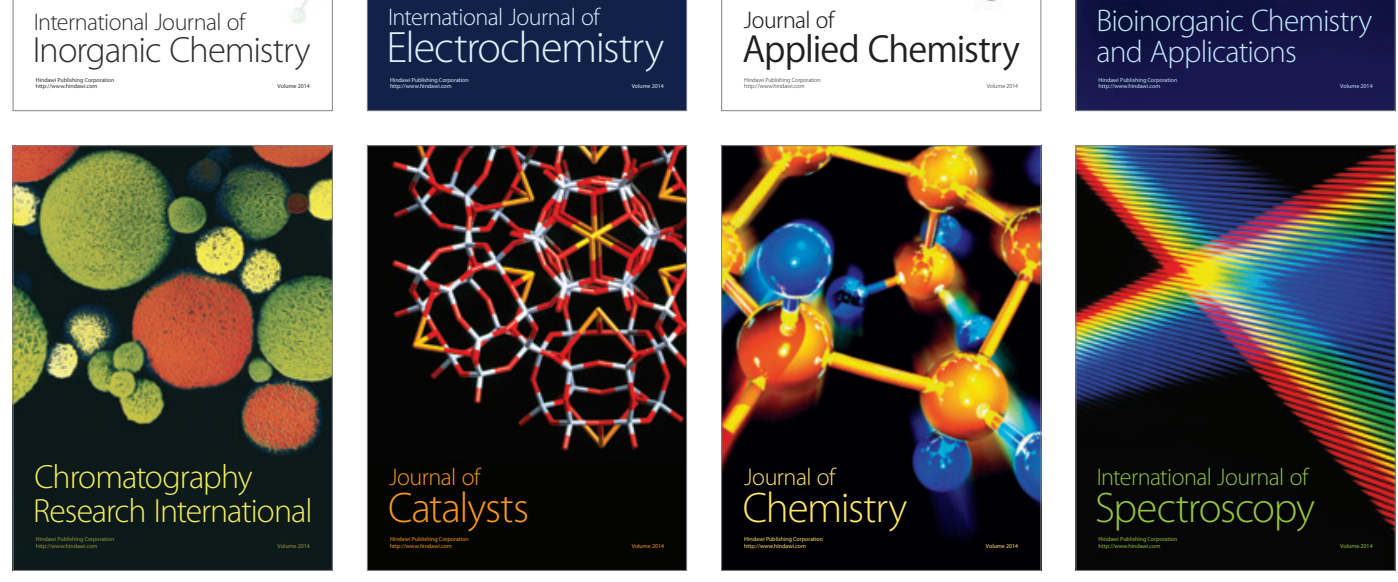